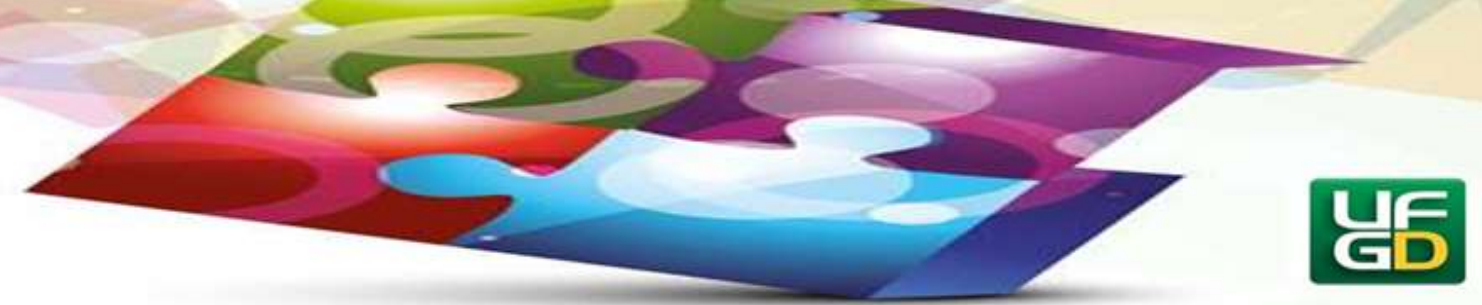

\title{
A CONSTRUÇÃO DE PRÁTICAS PEDAGÓGICAS DECOLONIAIS E SUA ARTICULAÇÃO COM OS PROCESSOS FORMATIVOS
}

\section{LA CONSTRUCCIÓN DE PRÁCTICAS PEDAGÓGICAS DECOLONIALES Y SU CONJUNCIÓN CON LOS PROCESOS FORMATIVOS}

Pedro RAUBER ${ }^{1}$

Resumo: Ancorado na concepção teórico-metodológica dos Estudos Culturais de orientação pós-estruturalista e da interculturalidade crítica decolonial, o artigo objetiva refletir sobre as práticas pedagógicas voltadas para as identidades culturais na perspectiva decolonial e suas articulações com os processos formativos de professores/as. Os dados que fundamentam as análises e reflexões resultam da pesquisa de doutorado em Educação do Programa de PósGraduação em Educação - Mestrado e Doutorado da UCDB realizada com professores/as egressos/as do curso de Pedagogia UEMS que atuam na Educação Infantil e anos iniciais do Ensino Fundamental em Dourados - MS. As percepções alcançadas a partir das observações, entrevistas e grupo de discussão, os/as professores/as tem dificuldades em abordar de forma mais ampla e aprofundada a temática, mas se mostram abertos/as a processos formativos sobre temática e revelarem concepções de identidades/diferença não essenciais e fixas, o que sinaliza a emergência de práticas que se aproximam da interculturalidade crítica e decolonial. Concluímos que o curso de Pedagogia foi fundamental para a construção e desenvolvimento de estratégias para abordar as identidades/diferenças. Entretanto, dada a complexidade da temática, um processo formativo na ótica da interculturalidade crítica decolonial as qualificaria ainda mais frente às exigências cada vez mais desafiadoras que o atual contexto sociopolítico multicultural exige.

Palavras-chave: Identidades/Diferenças. Estudos Culturais. Interculturalidade crítica decolonial.

Resumen: Anclado en la concepción teórico-metodológica de los Estudios Culturales con orientación postestructuralista e interculturalidad crítica decolonial, el artículo pretende reflexionar sobre las prácticas pedagógicas orientadas a las identidades culturales en la perspectiva descolonial y sus articulaciones con los procesos de formación docente. Los datos que sustentan los análisis y reflexiones son el resultado de la investigación de doctorado en Educación del Programa de Posgrado en Educación - Máster y Doctorado de la UCDB realizada con profesores de la carrera de Pedagogía de la UEMS que laboran en Educación Infantil y Educación Infantil. Escuela primaria en Dourados - MS. Las percepciones obtenidas

\footnotetext{
${ }^{1}$ Professor de Didática e Sociologia da Educação na Universidade Estadual de Mato Grosso do Sul (UEMS) em Dourados-MS. E-mail: rauber@uems.br.
} 


\section{HORIZONTES - REVISTA DE EDUCAÇÃO}

de las observaciones, entrevistas y grupo de discusión, los docentes tienen dificultades para abordar el tema de manera más amplia y profunda, pero están abiertos a los procesos de formación sobre el tema y revelan conceptos de identidades / diferencias no esenciales y fijas, lo que señala el surgimiento de prácticas que abordan la interculturalidad crítica y decolonial. Concluimos que el curso de Pedagogía fue fundamental para la construcción y desarrollo de estrategias para abordar identidades / diferencias. Sin embargo, dada la complejidad del tema, un proceso formativo desde la perspectiva de la interculturalidad crítica decolonial los calificaría aún más frente a las demandas cada vez más desafiantes que el contexto sociopolítico multicultural actual demanda.

Palabras-clave: Identidades/Diferencias. Estudios culturales. Interculturalidad crítica decolonial.

\section{Introdução}

Ancorado na concepção teórico-metodológica dos Estudos Culturais de orientação pós-estruturalista e na interculturalidade crítica decolonial, vistos aqui como campos que defendem os mesmos interesses e concebem as identidades/diferenças como construções cultuais, este trabalho objetiva analisar as concepções de professores/as sobre os processos formativos e refletir como estas se articulam com a construção de práticas pedagógicas voltadas para as identidades/diferenças culturais no espaço escolar na perspectiva decolonial.

Os dados que fundamentam as análises e reflexões são resultantes das observações, entrevistas e de um grupo de discussão realizadas na pesquisa de doutorado ${ }^{2}$ vinculado ao Programa de Pós-Graduação em Educação - Mestrado e Doutorado da UCDB de Campo Grande - MS, realizadas com oito professores/as egressos/as do curso de pedagogia da Universidade estadual de Mato Grosso do Sul - UEMS - que atuam na Educação Infantil e anos iniciais do Ensino Fundamental em Dourados - MS.

\footnotetext{
2 Este artigo foi produzido a partir da Tese de Doutorado "Práticas Pedagógicas voltadas para as Identidades/Diferenças e sua articulação com os processos Formativos: um estudo com professores egressos do Curso de Pedagogia da UEMS/Dourados", defendido em 2017 no Programa de Pós-Graduação - Mestrado e Doutorado em Educação da Universidade Católica Dom Bosco, Campo Grande - MS. Buscando compreender como os/as professores/as lidam em suas práticas pedagógicas com os saberes que se colocam a serviço da cultura hegemônica ocidental colocando sob suspeita, interrogam, transgridem, subvertem, ou não, representações hierárquicas e assimétricas da colonialidade ainda presentes no currículo escolar. Tese disponível em: http://site.ucdb.br/public/md-dissertacoes/1017780-pedro-rauber-tese-cd.pdf
} 


\section{HORIZONTES - REVISTA DE EDUCAÇÃO}

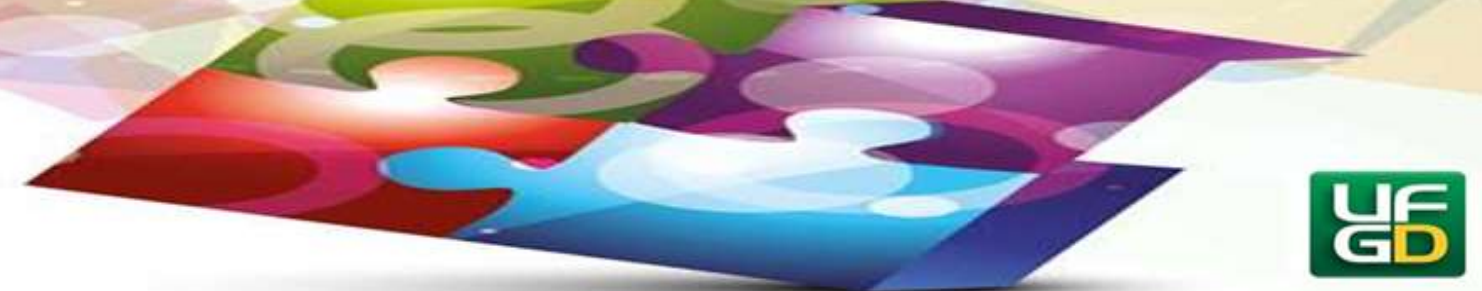

A interculturalidade, de acordo com Walsh (2009), é um projeto cultural, ético, social, político e epistêmico decolonial proposto pelo grupo "modernidade-colonialidade" que somente passa a ter significado e impacto na medida em que, assumida de maneira crítica, centra suas análises a partir do problema estrutural-colonial-racial e nas relações de poder para colocar sob suspeita estruturas e ordenamentos da sociedade que racializam, diminuem e desumanizam.

Este grupo é constituído por especialistas que centram suas análises no processo histórico de formação do continente latino-americano, um processo orientado pela afirmação de racionalidades outras, notadamente fora da lógica da modernidade euro-usa-centrica. No campo da educação a atenção de suas análises volta-se para as funções que a educação escolar exerceu na difusão e na consolidação de relações culturais, sociais e de poder em suas dimensões étnicas, de raça, de classe, de gênero, de orientação sexual da cultura ocidental.

A construção dos estados nacionais no continente latino-americano supôs um processo de homogeneização cultural em que a educação escolar exerceu um papel fundamental, tendo por função difundir e consolidar uma cultura comum de base ocidental e eurocêntrica, silenciando e/ou inviabilizando vozes, saberes, cores, crenças e sensibilidades (CANDAU; RUSSO, 2010, p. 154).

Cientes da polissemia de sentidos que o conceito de interculturalidade crítica e decolonial podem assumir, assumimos neste trabalho, a perspectiva da educação intercultural e decolonial concebidos como projetos que caminham juntos e que transcende a educação escolar indígena e que passou para uma abertura às diferenças étnicas, culturais e linguística. A interculturalidade crítica concebida como um elemento fundamental na articulação políticas de igualdade com políticas de identidade. Da mesma forma, decolonialidade como projeto e esforço para articular e interculturalizar os seres, o conhecimento, as formas e a lógica de viver, coexistir e "com-viver" dentro de um projeto múltiplo, variado e multiplicativo.

A interculturalidade crítica decolonial sugere a ideia de ouvir as vozes daqueles que estão nas fronteiras da exclusão, de diálogo, negociação, intercâmbio, interdependência entre pessoas e culturas baseada no princípio fundamental de igualdade de condições e contribuirão para a desconstrução de visões estereotipadas de gênero, raça e classe. 


\section{MORIZONTES - REVISTA DE EDUCAÇÃO}

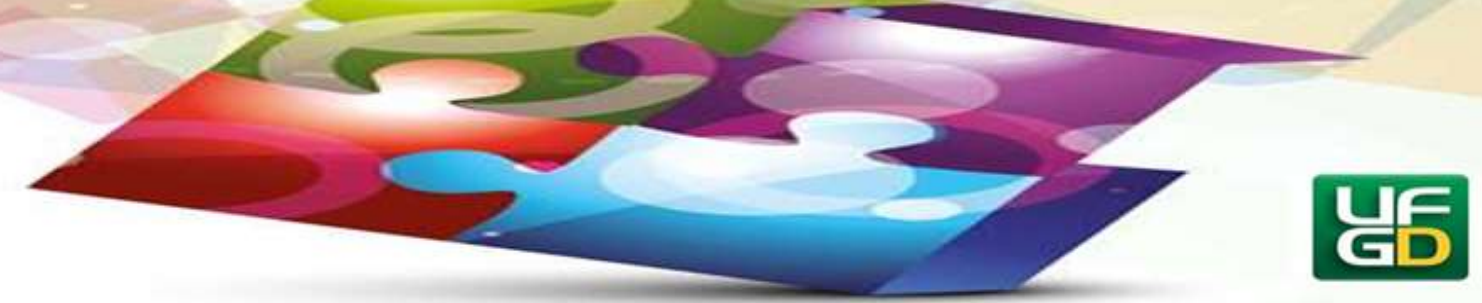

[...] ao colocar em debate e questionar as formas como se deu o estabelecimento das relações desiguais, assimétricas e de subalternização entre os gêneros, dá visibilidade às formas como as desigualdades e as inferiorizações foram construídas e naturalizadas. Além disso, ela também ajuda os alunos a compreender como estes dispositivos de poder, saber, ser e viver produzem e implantam em nós posições, práticas, concepções e pensamentos, que podem ser modificadas pela interculturalidade crítica como ferramenta pedagógica capaz de alentar forças, iniciativas e perspectivas para questionar, transgredir, transformar, rearticular e construir iniciativas decoloniais que problematizam e desafiam a noção de um pensamento e conhecimento totalizante, único e universal (RAUBER, 2017, p. 172).

Uma educação intercultural crítica decolonial exige pensar e repensar práticas pedagógicas "outras" e que direcionam o foco de suas discussões para a complexidade, a multiplicidade e a riqueza que as inter-relações entre os diferentes grupos culturais sustentada na possibilidade de não apenas coexistir, mas de viver "com". Uma educação que rejeita, denuncia e refuta as mais variadas formas de discriminação e de preconceito, visa potenciar "processos de empoderamento, principalmente de sujeitos e atores inferiorizados e subalternizados e a construção da autoestima, assim como estimula a construção da autonomia num horizonte de emancipação social" (CANDAU, 2012a, p. 129).

No que diz respeito à educação, a interculturalidade crítica decolonial, visa criar outras condições de poder, saber, ser, estar, viver e conviver que apontem para a possibilidade de empoderamento de sujeitos e de atores inferiorizados e subalternizados. Isto supõe a construção de práticas pedagógicas que devem partir do reconhecimento das diferenças presentes na escola e na sala de aula que homogeneízam, inferiorizam, silenciam, invisibilizam, negam, ocultam as diferenças.

A decolonialidade se expressa na interpelação da diferença colonial que operou na definição da matriz espaço temporal e codificou as diferenças entre conquistadores e conquistados. Ela interpela uma suposta estrutura biológica natural em que os conquistadores seriam constituídos naturalmente de capacidades de conquista e dominação, enquanto que os "outros" teriam naturalmente uma inclinação ao trabalho e à submissão. A interpelação dessa estrutura política e de poder colonial propõe a crítica e o reordenamento geopolítico da lógica de mundo produzida pelo colonialismo fundamentado na tradição ocidental e eurocêntrico (RAUBER, 2017, p. 180).

Ao questionar os processos de subalternização e inferiorização, invisibilização que determinados grupos culturais sofreram frente às condições a que foram submetidos ao longo 


\section{MORIZONTES - REVISTA DE EDUCAÇÃO}

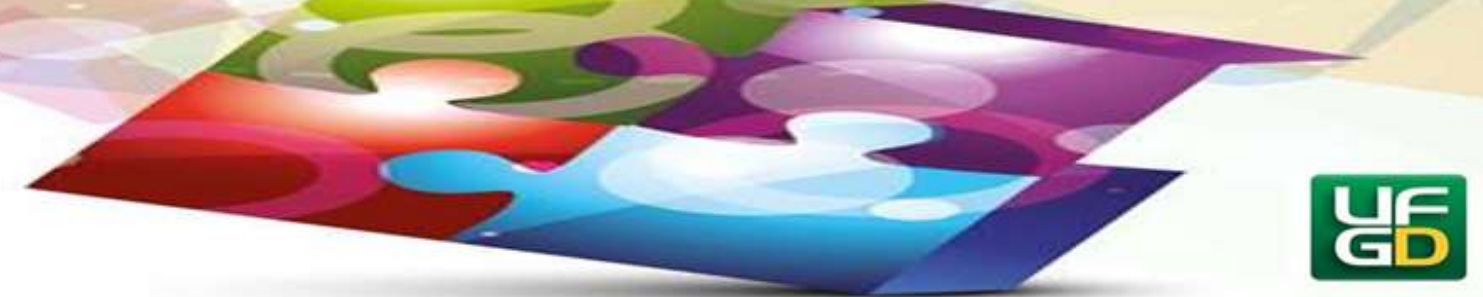

da história, a interculturalidade crítica na perspectiva decolonial visa garantir o ingresso, permanência e sucesso na educação escolar de sujeitos historicamente inferiorizados, subalternizados e silenciados na cultura escolar.

\section{Desafios para articular, a partir da perspectiva intercultural crítica, práticas pedagógicas decoloniais}

Assumir a perspectiva intercultural crítica decolonial como forma de potencializar os processos de aprendizagem escolar emancipatórios supõe a "desconstrução de práticas naturalizadas e enraizadas no trabalho docente" (CANDAU, 2012a, p. 130) pelo exercício de autorreflexão e de autoanálise.

Ao estimular professores/as e alunos/as a se interrogarem quem se situa na categoria de "diferente", é possível engendrar mecanismos através dos quais se trona possível infiltrar, fragilizar e romper processos coloniais de homogeneização de caráter monocultural que continuam a invisibilizar, inferiorizar e ocultar as diferenças nas relações entre os sujeitos no espaço e no currículo escolar (CANDAU, 2012b).

As práticas culturais, de acordo com Hall (1997), não teriam efeitos reais fora da "cultura" em que são produzidas. A cultura é parte constitutiva do "político" e a identidade como a diferença não são produtos da natureza. Na perspectiva dos estudos culturais, as identidades são entendidas não como uma essência, estáveis, fixas, homogêneas, acabadas. Os Estudos Culturais representam para nós como um campo comprometido com a realização de estudos, análises e diálogos abertos e instigantes que permitem construir possibilidades e estabelecer produtivas e instigantes aproximações entre cultura, educação e poder para descrever-analisar nossos objetos a partir de diferentes campos do saber para compreender e dizer algo diferente sobre eles e a partir deles sobre a forma como os processos formativos se articulam com as práticas voltadas para a produção de identidades/diferenças no espaço escolar (PARAÍSO, 2014). 


\section{MORIZONTES - REVISTA DE EDUCAÇÃO}

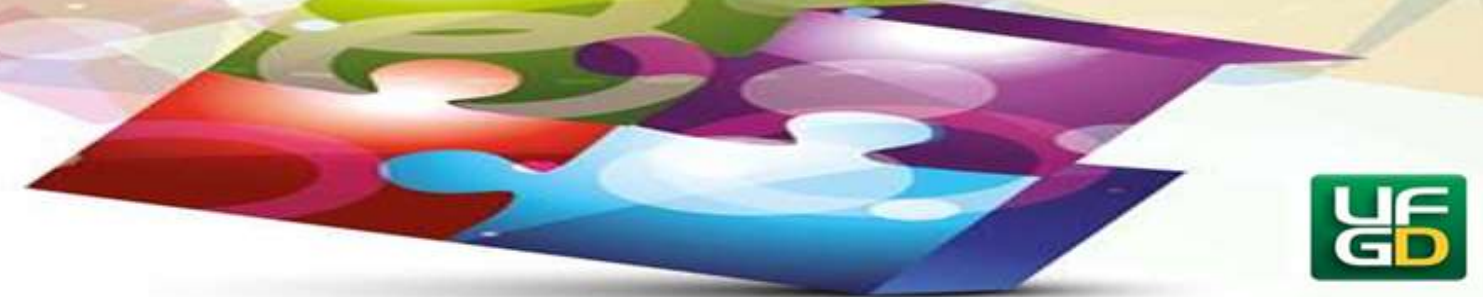

Ao operar desta forma é possível estabelecer produtivas aproximações que nos ajudam a construir um instrumento, uma lógica que possibilite compreender as movimentações discursivas que se engajam em torno delas que inventam, produzem e instituem identidades fazendo para isso uso não de uma teoria a subsidiar e nem de um único método a seguir, mas, de uma bricolagem de métodos, uma "total desterritorialização, que exige a invenção de outros e novos territórios" (PARAÍSO, 2014, p. 35).

Sendo uma construção cultural e social as identidades são mutantes, fluidas, deslizantes e que se forja e se produz no contexto cultural e nas relações sociais e de poder, produzidas a partir de valores socialmente atribuídos, constantemente interpeladas, pressionadas colocadas à prova por diferentes representações sociais e culturais que funcionam fundamentalmente como processos de significação, produzidas ao longo de nossa vida (BACKES, 2005).

Ao entender a identidade como uma produção, compreendemos também a escola como central na produção das identidades. Uma instituição produtora e instituidora de sentidos, efeitos e dispositivos de poder, de territorialização de subjetividades que geram implicações discursivas, nas quais a escola tem papel preponderante. Neste sentido, a identidade, tal como a diferença, é uma relação social [...] está sujeita a valores de força, a relações de poder" (SILVA, 2013b, p. 81).

A tarefa da análise cultural a partir dos processos formativos consiste, portanto, em questionar e interrogar a identidade e a diferença, em desconstruir, em expor os processos de naturalização. Ao questionar, problematizar, interrogar e colocar em xeque os processos pelos quais as fronteiras e diferenças foram nomeadas, demarcadas, classificadas, normalizadas pelo poder, torna-se possível compreender que o Outro se torna um problema, pois coloca permanentemente em xeque nossa própria identidade (SILVA, 2013b).

Nesta perspectiva, a dimensão da análise cultural que a escola exerce assume especial relevância, uma vez que a cultura se faz presente em todos os âmbitos da vida escolar. Por isso, o estudo do espaço escolar como um espaço de produção de identidades/diferenças, representa uma possibilidade instigante de pesquisa para quem se atreve analisar, reconhecer, potencializar, a partir do chão da escola, processos pedagógicos e de aprendizagem mais 


\section{MORIZONTES - REVISTA DE EDUCAÇÃO}

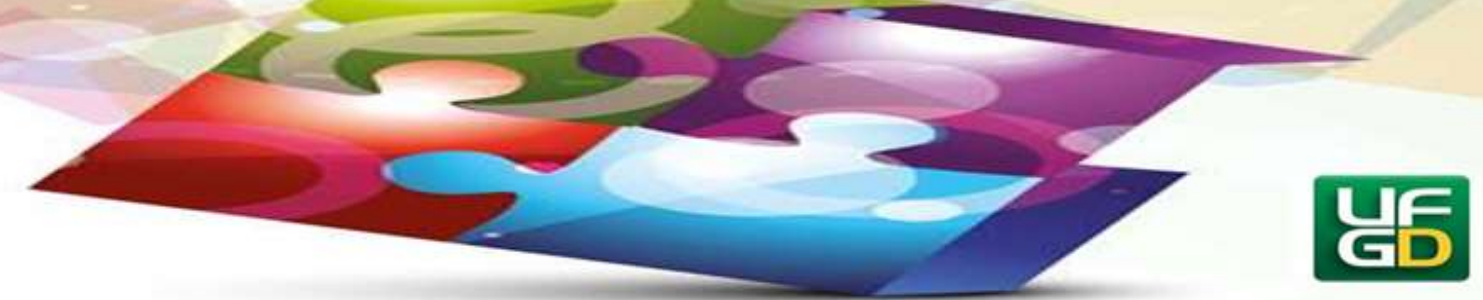

significativos e produtivos das identidades e diferenças presentes no dia a dia, uma vez que a educação e os processos educativos potencializam processos de aprendizagem

na medida em que reconhece e valoriza a cada um dos sujeitos neles implicados, combate todas as formas de silenciamento, invisibilização e/ou inferiorização de determinados sujeitos socioculturais, favorecendo a construção de identidades culturais abertas e de sujeitos de direito, assim como a valorização do outro, do diferente, e o diálogo intercultural (CANDAU, 2011, p. 253).

Ao recorrer aos Estudos Culturais buscamos compreender como os professores egressos do curso de Pedagogia da UEMS articulam concepções, práticas e processos de diálogos decoloniais entre diferentes saberes voltados a valorizar sujeitos e identidades socioculturais subalternizados, invisibilizados e negados no espaço escolar, o fazemos como forma de interrogar, questionar e colocar sob suspeita, praticas monoculturais produzidas sob o logos da modernidade. Uma vez que buscamos compreender a partir da interculturalidade crítica e decolonial os sentidos e significados que as professoras dão às suas práticas para analisar como elas lidam e articulam a partir da sala de aula essas concepções em suas práticas voltadas para as identidades/diferenças.

\section{Problematizar e articular, a partir da sala de aula, as complexas relações das identidades e diferenças culturais}

Tendo presente o que propomos neste artigo: refletir, a partir da interculturalidade crítica e dos Estudos Culturais, sobre as formas como os/as professores/as egressos do curso de pedagogia da UEMS problematizam e articulam saberes, discursos e práticas decoloniais na construção de identidades e diferenças no espaço escolar como forma de infiltrar, fragilizar e desconstruir perspectiva monoculturais produzidas sob o logos da modernidade.

É preciso esclarecer que ir "a campo" para fazer as observações em sala de aula foi para mim uma experiência impar ao exercitar e treinar o olhar de pesquisador sobre a sala de aula como um espaço que, num primeiro momento me parecia "um espaço comum, e 


\section{MORIZONTES - REVISTA DE EDUCAÇÃO}

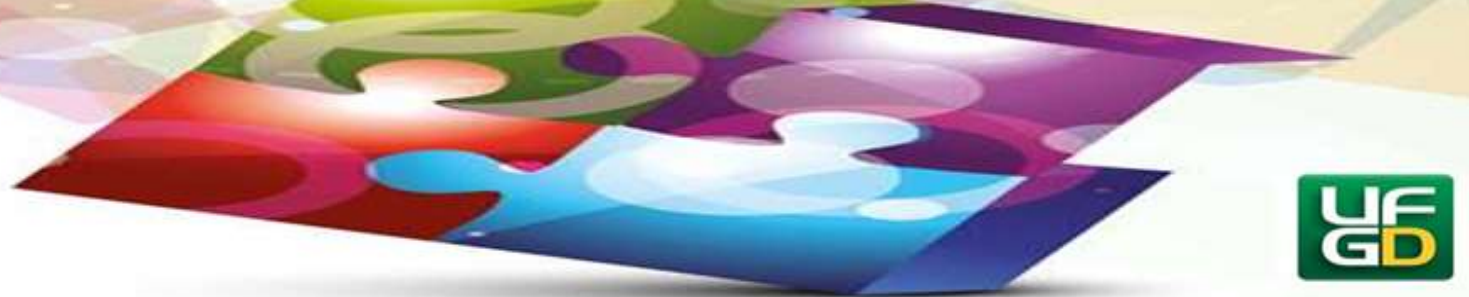

conhecido", mas, à medida que as observações se seguiam, percebi esse um espaço surpreendente para novos aprendizados.

Nas aulas de "Raciocínio Lógico-Matemático", com a professora Cristiane ${ }^{3}$ que trabalha de forma lúdica, observei uma proximidade maior em seus diálogos com as meninas. Esta postura parece levá-las a se envolverem mais nas atividades escolares ao passo que os meninos, parece ficarem mais "soltos", fato que leva eles a caminharem pela sala se ocuparem com conversas paralelas, brincadeiras e jogos corporais que, algumas vezes, chegam a ser agressivos. Isto torna a sala bastante movimentada e ruidosa e leva a professora a ter que interromper com certa frequência as atividades para chamar atenção da turma.

Ao abordar questões relativas às representações sobre identidade e diferenças culturais, Candau (2012b) aponta que muitas pesquisas descrevem e denunciam situações em que alunas/os com determinadas marcas identitárias são ignoradas, rejeitadas/os, ou até mesmo passam a ser objeto de discriminações e por isso são ignorados no dia a dia das nossas escolas.

Louro (2010), referindo-se às relações de gênero interroga:

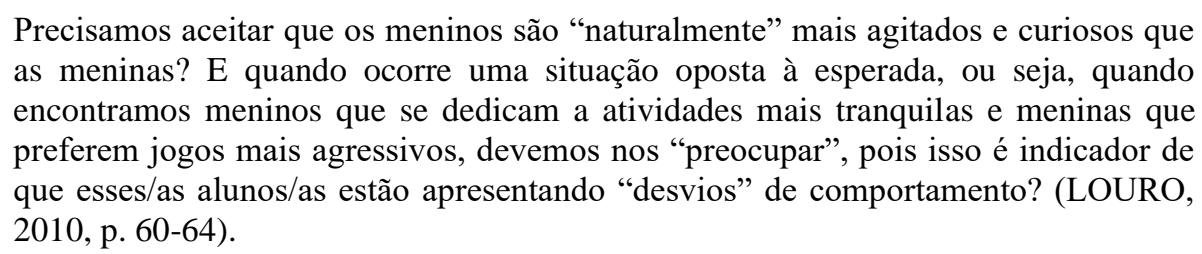

A forma como aparecem as teorias, as linguagens, os conteúdos, os procedimentos de ensino e a avaliação, constituem-se seguramente em "locus das diferenças de gênero, sexualidade, etnia, classe - são constituídos por essas distinções e, ao mesmo tempo, seus produtores" (LOURO, 2010, p. 64).

Já a professora "Célia" que trabalha com "Patrimônio Cultural - Formação pessoal, social e conhecimento de mundo" organiza com certa frequência trabalhos em grupos que mudam todos os dias de acordo com a ordem de chegada na sala. Essa disposição das

\footnotetext{
${ }^{3}$ Para preservar a identidade dos sujeitos da pesquisa, usamos nomes fictícios.
} 


\section{MORIZONTES - REVISTA DE EDUCAÇÃO}

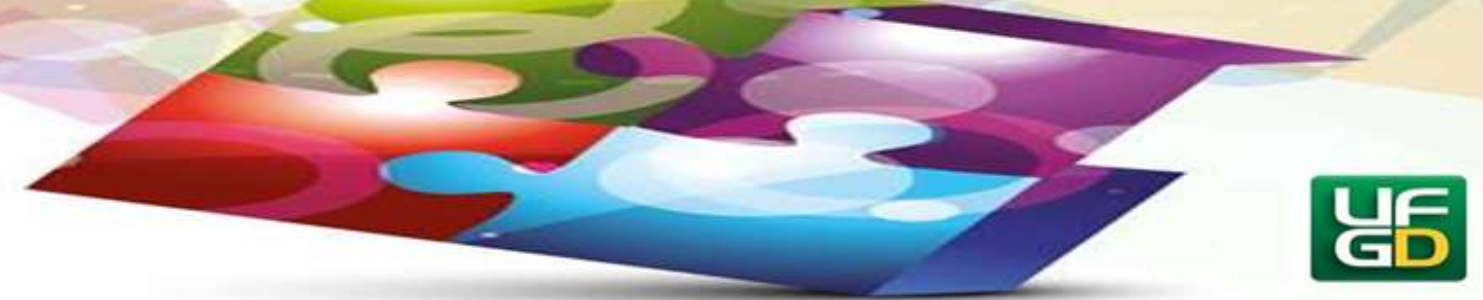

carteiras, de acordo com a professora, foi a maneira que ela encontrou para integrar "Welington" (cadeirante e tem dificuldades de falar) e levar todas as crianças a interagir com ele.

Segundo a professora, esta forma de organizar a sala, mudou o comportamento da turma com o Welington. "No começo do ano, ninguém queria sentar com ele. Era rejeitado, ficava isolado. Hoje as crianças já aceitam e o chamam para seu grupo".

A professora "Célia" trabalha com frequência a partir de histórias infantis que ela lê para a turma. Um dia, após contar uma história, ela sugeriu que as crianças ilustrassem o que elas haviam entendido. Ao pintar a ilustração que um grupo havia feito sobre a história, uma criança interrogou à professora sobre a cor com que elas deveriam pintar a personagem. "Da cor da pele" respondeu outra criança. "Mas o que é a cor de pele crianças"? Interrogou a professora. Um instante de silêncio. ... Logo algumas crianças levantaram o lápis de cor rosa. Novo silêncio... "Como assim?" interrogou a professora.

Neste momento a professora interveio e perguntou quem gostaria de vir à frente para conversar melhor sobre o assunto (cinco crianças foram à frente) e a professora perguntou: "Com que cor vocês representariam a cor da pele destes colegas de vocês?" Silêncio na sala. ... A professora colocou então uma criança um pouco à frente e colocou lápis de cores diferentes sobre um dos braços de cada uma das cinco crianças que estavam à frente. Novamente silencio... Após alguns instantes, as opiniões se dividiram sobre a "cor de pele".

Com esta demonstração as crianças foram se dando conta de que não haveria como determinar uma cor como sendo "a cor de pele". Ao interrogar as crianças sobre algo que já estava naturalizado é possível questionar, estimular e potenciar a análise e provocar a reflexão sobre situações que interferem nas formas de ser e de se relacionar no mundo.

É neste sentido que Oliveira; Abramowicz (2010) ao analisarem como as práticas educativas produzem e revelam a questão racial com crianças em creches apontam como os profissionais, desde a educação infantil podem reforçar o preconceito e o racismo, ou podem escapar da ordem hegemônica com práticas que

questionem suas práticas pedagógicas cotidianas, que, muitas vezes atreladas a um fazer acrítico, reforçam situações de racismo que interferem na constituição da 


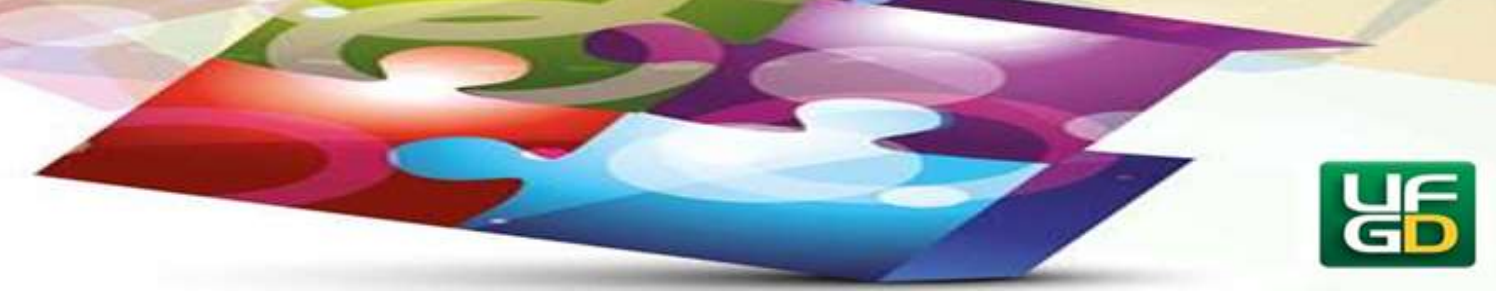

autoestima positiva das crianças negras, de seu pertencimento étnico e da construção de uma sociedade mais plural e democrática, visando a que todos tenham seus direitos garantidos, inclusive de aprendizagem e de respeito por suas raízes étnicas e raciais. Ou seja, os professores necessitam escapar da ordem hegemônica produtora de desejos, estéticas, prisioneiros para realizar práticas educativas que acolham e produzem diferença, como estratégia pedagógica (OLIVEIRA; ABRAMOVICZ, 2010, p. 224).

Ao agir assim a professora leva as crianças a refletirem sobre suas atitudes e favorece a troca, o intercambio, o reconhecimento mútuo e possibilita a desconstrução de preconceitos de caráter monocultural já interiorizados e naturalizados e que invisibilizam e ocultam as diferenças. "É importante que as práticas educativas partam do reconhecimento das diferenças presentes na escola e na sala de aula" (CANDAU, 2012a, p. 129).

Os pesquisadores engajados no campo da pesquisa educacional que se identificam com a perspectiva decolonial, ao assumirem a interculturalidade crítica como forma de desenvolver uma atitude aberta e questionadora em relação às visões essencializadas de identidades e de educação produzidas na colonialidade, buscam compreender como as diferenças culturais, raciais, étnicas e de poder entre os diferentes grupos socioculturais, étnico-raciais, sexuais, religiosos, de gênero, entre outros, foram construídas ao longo da história.

Com isso a interculturalidade crítica decolonial propõe, empoderar pela educação, os diferentes grupos socioculturais, religiosos, étnico-raciais, de gênero, orientação sexual, mas que a cultura hegemônica do pensamento e do conhecimento produzido no contexto euro-usacêntrico a partir da modernidade insiste em disseminar como forma de dominar e subalternizar (CANDAU, 2012a).

Romper com essa lógica implica assumir, no âmbito pedagógico, a disposição em assumir práticas e processos que buscam colocar sob suspeita estruturas, instituições, grupos e sujeitos historicamente produzidos. E, no âmbito da formação do ser humano, a sala de aula pode tornar-se um espaço privilegiado para levar as crianças a compreender que, do ponto de vista antropológico, o ser humano sempre demonstrou a preocupação em compreender a realidade para assim assumir a disposição em lutar contra toda e qualquer forma de preconceito, discriminação, racismo e desigualdade social bem como para lutar por condições 


\section{MORIZONTES - REVISTA DE EDUCAÇÃO}

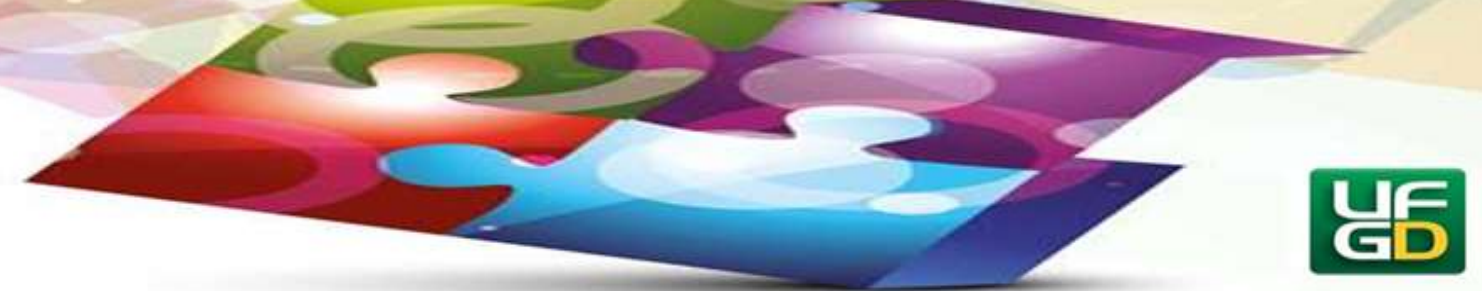

de vida digna para todos e por uma sociedade mais justa, igualitária e democrática a partir das práticas escolares.

Uma pedagogia intercultural crítica adquire concretude de decolonialidade no coletivo da escola quando as relações que se estabelecem entre professores/as e educandos/as evitam processos de discriminação, inferiorização, e negação que permeiam as relações sociais de saber/poder no espaço escolar. A interculturalidade crítica decolonial, requer construir práticas e concepções que não se limitem simplesmente ao "tratamento normal/igual" (RAUBER, 2017).

Os processos formativos têm um papel fundamental no processo de formação para o empoderamento de professores/as na construção de práticas pedagógicas interculturais críticas decoloniais ao colocarem em questão, desde a formação inicial como também na formação permanente, as visões monoculturais essencializadas, naturalizadas e inferiorizadas que circulam na cultura escolar hegemônica.

No entanto um trabalho pedagógico nesta perspectiva exige também o reconhecimento de que os estudos e debates neste campo não são consensuais e nem podem ser construídos por uma abordagem epistêmica, ética, social ou teórico-metodológica única e muito menos representam a totalidade das possibilidades conceituais. Uma vez que, se é por meio da cultura que os seres humanos, atribuem valores, normas e significados às coisas e às condutas que modelam, regulam e instituem sentidos às práticas sociais e às suas condutas. Uma vez que a cultura "é um campo onde se define não apenas a forma que o mundo deve ter, mas também a forma como as pessoas e os grupos devem ser" (SILVA, 2013a, p. 134).

\section{Considerações finais}

Os Estudos Culturais constituem-se em importante e poderoso meio através do qual se torna possível provocar "microrrevoluções na educação" (BACKES, 2005, p. 48) através das quais é possível desmistificar as concepções elitistas e hegemônicas de cultura colonial e que servem como instigante fonte de pesquisa e meio para análise para compreender as formas pelas quais "a escola moderna se tornou um espaço privilegiado de governo, regulação e 


\section{HORIZONTES - REVISTA DE EDUCAÇÃO}

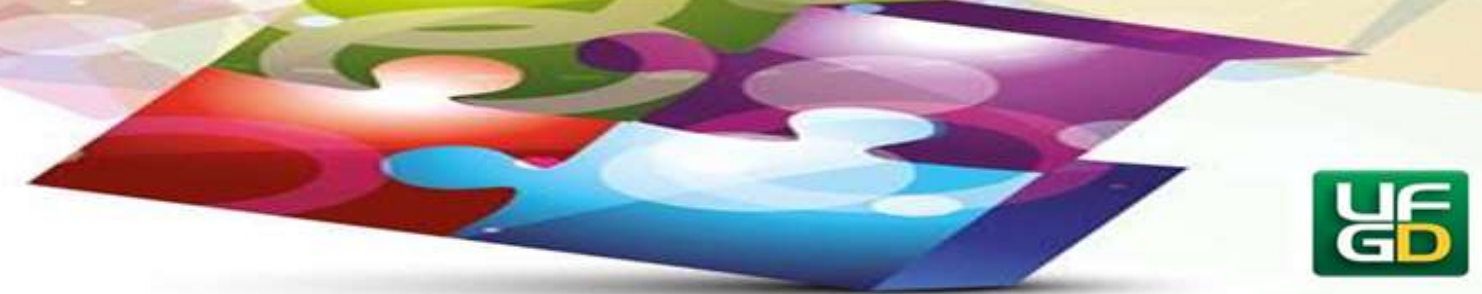

controle das identidades, produzindo identidades etnocêntricas, machistas e brancas" (BACKES, 2005, p. 48).

A problematização torna possível interrogar, desmistificar ampliar e aprofundar entendimentos que possibilita análises, reflexões e debates políticos que ajudam a construir posturas éticas e mudar nosso olhar sobre a diversidade na busca da afirmação de direitos e a busca permanente por uma posição de diálogo entre as diferentes culturas. Bem como para ampliar e aprofundar a discussão sobre as relações de poder vigentes na sociedade para o empoderamento e a emancipação social de sujeitos e atores historicamente inferiorizados e subalternizados.

No entanto, tal postura não se constrói no isolamento. Ela precisa ser engendrada e construída nas relações com o outro. Ela não se fecha na norma moral do "deveria ser", do "certo" ou do "errado", mas na capacidade de problematizar, de refletir, de buscar novas informações e posicionamentos, de confrontar, no diálogo, posições, tomar decisões e se reconhecer como ser humano no mundo como sujeito que tem o direito de respeitar e ser respeitado, reconhecido e valorizado como tal.

Assumir uma dimensão pedagógica crítica decolonial requer que a educação cumpra o papel de levar os sujeitos a questionarem as relações sociais e de poder produzidas na modernidade como também sejam capazes de se questionarem permanentemente, a si mesmos nos seus preconceitos, bem como entender as identidades/diferenças não como essenciais e fixas, mas como passíveis de serem modificadas pelos processos formativos.

A pesquisa aponta que esse esforço em problematizar e articular discursos e práticas pedagógicas decoloniais já vem surtindo efeitos positivos nos/as professores/as egressos/as do curso de Pedagogia da UEMS. Tal efeito se manifesta quando as professoras se mostram preocupadas e comprometidas em introduzirem abordagens e práticas pedagógicas pelas quais interrogam as suas próprias práticas e ao mesmo tempo problematizam e fragilizam visões monoculturais presentes no currículo e nas práticas pedagógicas e valorizaram o reconhecimento das identidades/diferenças a partir do espaço escolar.

Concluímos que o curso de Pedagogia foi fundamental para o desenvolvimento de estratégias pedagógicas que vão além da aquisição de conteúdos acadêmicos na abordagem 


\section{MORIZONTES - REVISTA DE EDUCAÇÃO}

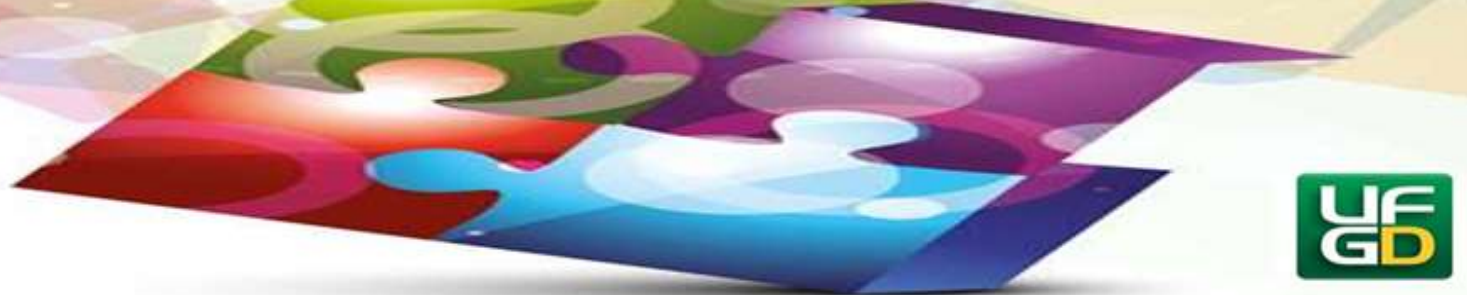

das identidades/diferenças. Ao desenvolver procedimentos de estudo, seleção e pesquisa de materiais de estudo as professoras vão além da informação e da reprodução.

A pesquisa possibilitou perceber que os/as professores/as, ao problematizar questões de convívio social, ajudam seus alunos a desenvolver valores, atitudes e procedimentos. Em suas análises já conseguem interrogar a estrutura colonial-racial e as relações de poder presentes na sociedade ao incentivarem as crianças a se posicionar de forma crítica e refletida com senso de responsabilidade, solidariedade, respeito ao próximo e compromisso social.

Todavia, é preciso alertar ainda que, a formação docente na perspectiva da interculturalidade crítica decolonial qualificaria ainda mais a prática docente frente as exigências cada vez mais desafiadoras que o atual contexto sociopolítico multicultural e globalizado exige.

\section{Referências}

BACKES, José Licínio. A negociação das identidades/diferenças culturais no espaço escolar. São Leopoldo, Tese (Doutorado) - Universidade do Vale do Rio dos Sinos, Centro de Ciências Humanas, Programa de Pós-Graduação em Educação, 2005.

CANDAU, Vera Maria Ferrão. Diferenças Culturais, Cotidiano Escolar e Práticas Pedagógicas. Currículo sem Fronteiras, v.11, n.2, p. 240-255, Jul/Dez 2011.

Escola, didática e interculturalidade: desafios atuais. In: CANDAU, Vera Maria Ferrão (org.). Didática crítica intercultural: aproximações. Petrópolis, RJ : Vozes, 2012a, p. 107-138.

Diferenças Culturais, Interculturalidade e Educação em Direitos Humanos. Educ. Soc., Campinas, v. 33, n. 118, p. 235-250, jan.-mar. 2012b. Disponível em http://www.cedes.unicamp.br Acesso em 12/08/2019.

CANDAU, Vera Maria Ferrão, RUSSO, Kelly. Interculturalidade e Educação na América Latina: uma construção plural, original e complexa. Rev. Diálogo Educ., Curitiba, v. 10, n. 29 , p. 151-169, jan./abr. 2010.

HALL, Stuart. A centralidade da cultura: notas sobre as revoluções culturais do nosso tempo. Educação \& Realidade, v. 22, n. 2, jul./dez., 1997. 


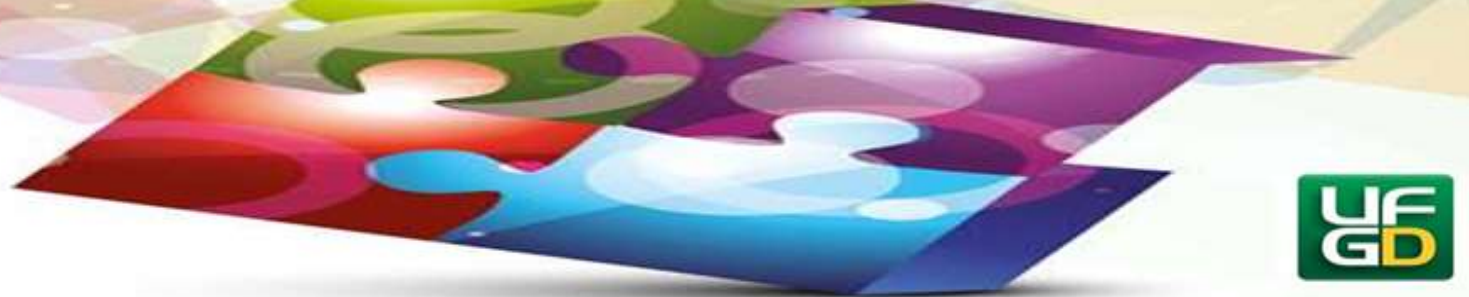

LOURO Guacia Lopes. Gênero, Sexualidade e Educação: uma perspectiva pósestruturalista. 11. ed. Petrópolis, RJ : Vozes, 2010.

OLIVEIRA, Fabiana de; ABRAMOVICZ, Anete. Infầncia, raça e "paparicação". Educação em Revista. Belo Horizonte, v. 26, n. 02. P. 209-226, ago. 2010.

PARAÍSO, Marlucy Alves. Metodologias de pesquisa pós-críticas em educação e currículo: trajetórias, pressupostos, preconceitos e estratégias analíticas, In.: MEYER, Dagmar Estermann; PARAÍSO, Marlucy Alves (Orgs.). Metodologias de pesquisa pós-críticas em educação. Belo Horizonte: Mazza Edições, 2014, p. 25-47.

RAUBER, Pedro. Práticas Pedagógicas voltadas para as identidades/diferenças e sua articulação com os processos formativos: um estudo com professores egressos do Curso de Pedagogia da UEMS/Dourados. Tese (Doutorado) Universidade Católica Dom Bosco, Campo Grande, 2017.

SILVA, Tomaz Tadeu da. Documentos de Identidade: uma introdução às teorias do currículo. 3. ed. 4. Reimp. Belo Horizonte: Autêntica Editora, 2013a.

SILVA, Tomaz Tadeu da (Org.). A produção social da identidade e da diferença. In:. SILVA, Tomaz Tadeu da. Identidade e diferença: a perspectiva dos Estudos Culturais.13 .ed. Petrópolis, RJ : Vozes, 2013b, p. 73-102.

Enviado: $30 / 06 / 2020$

Aceito: $31 / 08 / 2020$ 